\title{
DIVERSITAS DAN DISTRIBUSI IKAN DI SEGARA ANAKAN CILACAP
}

\author{
SUPRASTINI, ERWIN RIYANTO ARDLI, AgUS NURYANTO
}

Fakultas Biologi, Universitas Jenderal Soedirman, Jalan dr. Suparno 63 Purwokerto 53122

\section{A B S T R A C T}

Fish is one of the aquatic commodities with significant economic value, and Segara Anakan areas is a habitat for valuable fishes for local fisherman. Segara Anakan is a eutrophic waters and serves as nursery and spawning ground and also provide an optimal environment for several species fish larvae to grow, either sedentary or migratory species. Therefore it is suggested that diverse species inhabit Segara Anakan and different part of those areas has different species because different species commonly exhibit different habitat preferences. The objectives of this research were to determine the diversity and spatial distribution of fish species in Segara Anakan Cilacap. This research was a survey with the Cluster Random Sampling was implemented as sampling technique. Species diversity was analyzed descriptively, as well as the spatial distribution. The relationships between environmental parameters and spatial distribution were analyzed using Principal Component Analysis. Environmental factors such as temperature, pH, salinity, and water DO were measured. The result showed that Stolephorus indicus was the most dominant species in Segara Anakan. The spatial distribution of fishes in every sampling station was found fluctuated. The environmental factors and fish were found highly correlated.

KEY WORDS: fish, Segara Anakan, diversity, distribution

Corresponding Author: ERWIN RIYANTO ARDLI | email: erwin.ardli@unsoed.ac.id

\section{PENDAH ULUAN}

Segara Anakan merupakan ekosistem estuaria dengan muara yang menjadi pertemuan beberapa sungai di Jawa Tengah dan Jawa Barat seperti Sungai Citanduy, Cibeurem, Cikujang, Cikonde, Kayu Mati, Ujung Alang, Dangkal, Kembang Kuning, Sapuregel, dan Donan. Kawasan Segara Anakan terletak di pantai selatan Propinsi Jawa Tengah tepatnya di Kabupaten Cilacap atau di sebelah utara Pulau Nusakambangan pada koordinat $\quad 07^{\circ} 34^{\prime} 29.42^{\prime \prime} \mathrm{LS}-07^{\circ} 47^{\prime} 32.39^{\prime \prime} \mathrm{LS}$ dan $108^{\circ} 46^{\prime} 30.12^{\prime \prime}$ BT-109 03'21.02"BT. Luas wilayah Segara Anakan mencapai kurang lebih 34.018 ha (Ardli \& Wolff, 2008).

Estuaria Segara Anakan Cilacap merupakan lingkungan yang kaya akan sumberdaya hayati perairan termasuk ikan. Kondisi lingkungan estuaria sangat mendukung bagi perkembangan organisme perairan termasuk ikan karena estuaria baik secara fisik-kimiawi perairan maupun sebagai lingkungan kaya sumber pakan alami untuk perkembangan organisme perairan. Ekosistem estuaria merupakan salah satu habitat asuhan (nursery ground) yang penting dalam siklus hidup organisme perairan baik ikan maupun udang (McHugh, 1967 dalam Boehlert dan Mundy, 1988). Adanya aliran air dari laut dan sungai yang membawa berbagai materi organik dan anorganik sebagai nutrien guna berkembangnya fitoplankton (Eyre \& Ferqusan, 2006).

Berbagai penelitian menunjukkan bahwa daerah estuaria merupakan perairan yang subur dan berfungsi sebagai daerah asuhan dari berbagai jenis larva ikan, baik jenis ikan yang bersifat sedentary maupun migratory (Janekarn, 1986 dalam Subiyanto et al., 1995). Kondisi lingkungan estuaria sangat mendukung bagi perkembangan organisme perairan termasuk ikan karena estuaria baik secara fisikkimiawi perairan maupun sebagai lingkungan kaya sumber pakan alami untuk perkembangan organisme perairan.

Beberapa jenis komoditas hasil perikanan dari Segara Anakan adalah kepiting, udang, dan ikan. Ikan merupakan salah satu komoditas perikanan yang memiliki nilai ekonomi penting. Menurut Tomascik et al. (1997) terdapat 29 spesies ikan yang mewakili 18 familia terdapat di perairan Segara Anakan. Di antara 18 famiia yang ada, urutan dominasi familia yang ada adalah sebagai berikut Pomacentridae $(29,84 \%)$, Atherinidae (28,66\%), Gobiidae (20,31\%), Clupeidae $(11,19 \%)$, sedangkan untuk jenis ikan lainnya hanya ditemukan dalam jumlah yang sedikit, yaitu kurang dari 2\%, (Subiyanto, 2008). Kohno dan Sulistiono (1994) menyatakan bahwa jenis ikan banyak di temukan dari berbagai ukuran dari golongan ikan sedentary/restident dan ikan migratory di perairan Segara Anakan. Kesukaan dan tingkah laku ikan terhadap habitat tertentu berbeda-beda untuk ikan yang ukurannya tidak sama (Effendie, 1979).

Diversitas spesies adalah sifat komunitas yang diperlihatkan tingkat diversitas spesies organisme di dalamnya. Menurut Odum (1971) untuk memperoleh diversitas cukup diperlukan mengenal dan membedakan spesies meskipun tidak secara mendetail mengidentifikasi (Kreb, 1978).

Distribusi adalah pemencaran tata ruang individu yang satu terhadap individu lain dalam suatu populasi. Distribusi suatu spesies pada perairan sungai merupakan refleksi dari adaptasi organisme perairan terhadap perubahan kondisi lingkungan (Odum, 1993). Menezes dan Camaraschi (1999) menyatakan bahwa keberadaan dan distribusi ikan di sungai dipengaruhi oleh faktor biotik dan abiotik seperti : suhu, $\mathrm{pH}$, salinitas, tipe substrat, ketersediaan pakan dan strategi reproduksi. Spesies ikan yang berbeda mungkin menunjukkan preferensi habitat yang berbeda pula, menyebabkan pada suatu habitat 
akan terdiri dari kumpulan spesies yang berbeda (Capone \& Kushlan, 1991; Chipps et al., 1994).

Berdasarkan laporan dari Proyek Citanduy Departemen Pekerjaan Umum, sedimen yang dibawa ketiga sungai besar yaitu sungai Citanduy 5 juta $\mathrm{m}^{3}$, sungai Cimeneng 0,4 juta $\mathrm{m}^{3}$, dan sungai Cikonde 1,2 juta $\mathrm{m}^{3}$ setiap tahun akibat sedimentasi yang terus menerus dikhawatirkan permukaan air sungai Citanduy dan sungai-sungai lainnya yang bermuara di Segara Anakan terus meningkat dan mengakibatkan banjir di sekitar wilayah sungai. Selain itu juga pendangkalan akibat sedimentasi akan semakin mempercepat rusaknya ekosistem di Segara Anakan. Dilaporkan pula oleh Negara (2012) bahwa luas laguna Segara Anakan sekarang ini tinggal \pm 600 ha. Berdasarkan kondisi tersebut dikhawatirkan akan mengganggu kelestarian ikan. Oleh karena itu, diperlukan informasi mendasar mengenai ikan sebagai dasar dalam usaha pengelolaan sumber daya perikanan di Segara Anakan Cilacap.

Berdasarkan uraian di atas maka tujuan dari penelitian adalah: mengetahui diversitas ikan yang terdapat di Segara Anakan Cilacap, mengetahui distribusi spasial ikan yang terdapat di Segara Anakan Cilacap, dan mengetahui factor yang mempengaruhi diversitas dan distribusi spasial ikan di Segara Anakan Cilacap.

\section{METODE}

Penelitian dilakukan menggunakan metode survei dengan teknik pengambilan sampel cluster random sampling pada 7 stasiun dengan 3 kali ulangan. Pemilihan daerah tersebut sebagai wilayah sampling berdasarkan letak jaring apung nelayan dan koordinat yang diduga banyak terdapat ikan. Sampel ikan diambil dari beberapa nelayan yang sedang mengangkat jaring apung. Sampel ikan dimasukan ke dalam kantong plastik dan dimasukan ke dalam ice box. Kantong plastik yang berisi sampel ikan tersebut dibawa ke laboratorium untuk diidentifikasi. Ulangan dilakukan sebanyak 3 kali pada semua stasiun penelitian,

Pengukuran suhu udara dan air dilakukan di sekitar titik sampling. Pengukuran suhu udara dilakukan dengan menggantugkan termometer selama 10 menit di udara setelah itu dicatat. Pengukuran $\mathrm{pH}$ perairan dilakukan menggunakan kertas indikator $\mathrm{pH}$ universal. Pengukuran salinitas menggunakan salt refraktometer dengan cara meneteskan sampel air pada kaca refraktometer kemudian dilihat kisaran salinitasnya yang dinyatakan dengan satuan ppt (part per thousand) kemudian dicatat hasilnya. Pengukuran kandungan oksigen terlarut dilakukan dengan metode Winkler (Alaert dan Santika, 1987).

$$
\text { DO }=\frac{1.000}{100} \times \mathrm{p} \times \mathrm{q} \times 8 \mathrm{mgl}^{-1}
$$

Keterangan:

$$
\begin{aligned}
\frac{1000}{100} & =100 \mathrm{ml} \text { sampel air yang digunakan per } 1.000 \mathrm{ml} \\
\mathrm{p} & =\text { jumlah ml Na} \mathrm{S}_{2} \mathrm{O}_{3} \\
\mathrm{q} & =\text { normalitas larutan } \mathrm{Na}_{2} \mathrm{~S}_{2} \mathrm{O}_{3} \\
8 & =\text { bobot setara } \mathrm{O}_{2}
\end{aligned}
$$

Identifikasi ikan dilakukan dengan cara meletakkan ikan pada baki putih kemudian diamati bagian kepala, sirip, bentuk tubuh, dan ekor ikan. Identifikasi menggunakan buku Kottelat et al., (1997) dan FishBase (2012). Data diversitas dianalisis menggunakan analisis deskriptif. Distribusi ikan dilihat berdasarkan distribusi spasial. Selanjutnya untuk mengetahui hubungan spesies yang ditemukan dengan faktor lingkungan menggunakan analisis Principal Component Analysis.

\section{HASIL DAN PEMBAHASAN}

Diversitas ikan yang terdapat di Segara Anakan Cilacap dapat dikatakan cukup sedikit yaitu 17 spesies yang tergolong dalam 12 familia yaitu Bothidae, Cyoglossidae, Drepaneidae, Engraulidae, Haemulidae, Leiognathidae, Lutjanidae, Mugilidae, Trichiuridae, Sciaenidae, Platycephalidae dan Scatophagidae (Tabel 1). Stasiun II, III dan VI memiliki jumlah spesies tertinggi yaitu 10 spesies. Sedangkan jumlah spesies terendah terdapat di stasiun VII dengan jumlah 7 spesies.

Stolephorus indicus tersebar di seluruh stasiun penelitian kemudian diikuti oleh Valamugil bunchanani, Cynoglossus lingua dan Thryssa kammalensis masing-masing 5 stasiun. Nibea miichthioides, Platycephalus indicus, Otolithus ruber dan Lutjanus sp. masing-masing 4 stasiun. Crossorhombus azereus, Scatophagus argus, Liza subviridis, Drepane punctata, Leioghnatus equulus, Pomadasys maculatus masing-masing 3 stasiun. Leioghnatus lucicus 2 stasiun, Trichiurus lepturus dan Thryssa hamiltonii 1 stasiun.

Stasiun I, II, III, VI dan VII didominasi oleh Stolephorus indicus, sedangkan stasiun IV didominasi oleh Drepane punctate dan stasiun V didominasi Thryssa kammalensis. Famili Engraulidae terlihat memiliki jumlah spesies yang paling dominan yaitu 3 spesies, kemudian Leiognathidae (2 spesies), Scianidae (2 spesies) dan Mugilidae (2 spesies). Spesies dari famili Engraulidae yang berhasil terkoleksi yaitu Stolephorus indicus, Thryssa kammalensis dan Thryssa hamiltonii. Ketiga spesies ini merupakan ikan demersial di kawasan mangrove (Suprapto, 2008). Stolephorus indicus di semua stasiun menunjukan bahwa Stolephorus indicus mampu beradaptasi dengan baik di Segara Anakan Cilacap.

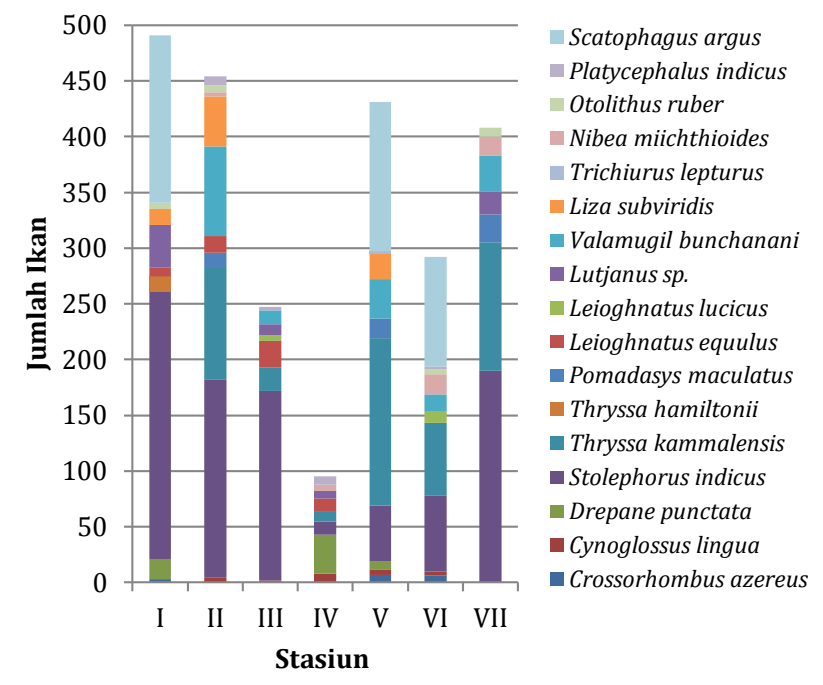

Gambar 1. Distribusi Ikan Tiap Stasiun Ikan 
Tabel 1. Spesies ikan yang ditemukan di Segara Anakan Cilacap

\begin{tabular}{ll}
\hline \multicolumn{1}{c}{ Familia } & \multicolumn{1}{c}{ Spesies } \\
\hline Bothidae & Crossorhombus azereus \\
\hline Cynoglossidae & Cynoglossus lingua \\
\hline Drepaneidae & Drepane punctate \\
\hline \multirow{2}{*}{ Engraulidae } & Stolephorus indicus \\
\cline { 2 - 2 } & Thryssa kammalensis \\
\hline Haemulidae & Thryssa hamiltonii \\
\hline Leiognathidae & Leioghnatasys maculatus \\
\hline Lutjanidae & Leioghnatus lucicus \\
\hline Mugilidae & Lutjanus sp. \\
\hline Trichiuridae & Valamugil bunchanani \\
\hline Sciaenidae & Liza subviridis \\
\hline Platycephalidae & Trichiurus lepturus \\
\hline Scatophagidae & Nibea miichthioides \\
\hline
\end{tabular}

Berdasarkan hasil penelitian distribusi ikan Engraulidae ditemukan hampir disemua stasiun penelitian Engraulidae mendominasi hampir di semua stasiun, berdasarkan pada tingkat keberadaan ikan pada saat pengambilan sampel, Stolephorus indicus menempati seluruh stasiun. Stolephorus indicus mempunyai distribusi yang tersebar merata di semua stasiun penelitian dengan jumlah individu terbesar pada stasiun I yaitu 240. Thryssa kammalensis terdistribusi di 6 stasiun dengan jumlah individu terbesar pada stasiun $\mathrm{V}$ yaitu 150. Berbeda dengan Stolephorus indicus dan Thryssa kammalensis, Thryssa hamiltonii hanya dijumpai pada stasiun I dengan jumlah individu 14.

Seperti halnya dengan Engraulidae, Sciaenidae, Leiognathidae dan mugilidae di temukaan hampir disemua stasiun. Distribusi Nibea miichthioides mempunyai jumlah individu terbanyak pada stasiun VI yaitu 18. Otolithus ruber terdistribusi di 4 stasiun dengan jumlah individu terbanyak pada stasiun VII yaitu 8. Leiognathidae terdistribusi di 4 stasiun untuk Leioghnatus equulus dengan jumlah individu terbanyak pada stasiun III yaitu 24. Sedangkan distribusi Leioghnatus lucicus terdistribusi di 2 stasiun dengan jumlah individu terbanyak pada stasiun VI yaitu 10. Valamugil bunchanani mempunyai distribusi yang hampir merata yaitu 5 stasiun dengan jumlah individu terbanyak pada stasiun II yaitu 80 . Sedangkan Liza subviridis terdistribusi di 3 stasiun dengan jumlah individu terbanyak terdapat pada stasiun II yaitu 45 .

Crossorhombus azereus terdistribusi di 3 stasiun dengan jumlah individu terbanyak terdapat pada stasiun V yaitu 7. Seperti halnya Crossorhombus azereus, Drepane punctata, Pomadasys maculatus, Scatophagus argus terdistribusi di 3 stasiun dengan jumlah individu terbanyak masing-masing 35 (stasiun IV), 25 (stasiun VII), 150 (stasiun I).

Cynogllosus lingua mempunyai distribusi hampir merata yaitu 5 stasiun dengan jumlah individu terbanyak pada stasiun IV yaitu 8. Lutjanus sp. terdistribusi di 4 stasiun dengan jumlah individu

\begin{tabular}{rrrrrrrr}
$\Sigma$ & \multicolumn{7}{c}{ Stasiun } \\
\cline { 2 - 8 } & I & II & III & IV & V & VI & VII \\
16 & 3 & - & - & - & 7 & 6 & - \\
23 & - & 4 & 2 & 8 & 5 & 4 & - \\
60 & 18 & - & - & 35 & 7 & - & - \\
908 & 240 & 178 & 170 & 12 & 50 & 68 & 190 \\
460 & - & 100 & 21 & 9 & 150 & 65 & 115 \\
14 & 14 & - & - & - & - & - & - \\
57 & - & 14 & - & - & 18 & - & 25 \\
\hline 58 & 8 & 15 & 24 & 11 & - & - & - \\
15 & - & - & 5 & - & - & $1-$ & - \\
76 & 38 & - & 10 & 7 & - & - & 21 \\
175 & - & $8-$ & 12 & - & 35 & 16 & 32 \\
\hline 82 & 14 & 45 & - & - & 23 & - & - \\
2 & - & - & - & - & 2 & - & - \\
45 & - & 4 & - & 6 & - & 18 & 17 \\
24 & 6 & 6 & - & - & - & 4 & 8 \\
\hline 21 & - & 8 & 3 & 7 & - & 3 & - \\
382 & 150 & - & - & - & 134 & 98 & - \\
& & & - & & & &
\end{tabular}

terbanyak pada stasiun I yaitu 38. Platycephalus indicus terdistribusi di 4 stasiun dengan jumlah individu terbanyak pada stasiun II yaitu 8. Trichiurus lepturus hanya terdistribusi di 1 stasiun yaitu stasiun $\mathrm{V}$ dengan jumlah individu 2.

Jumlah individu ikan selama pengambilan sampel pada stasiun I-VIII selalu berfluktuasi. Hal ini berkaitan dengan migrasi ikan mencari kondisi lingkungan yang sesuai dan kebutuhan makanan untuk pertumbuhannya. Selain itu juga karena keberadaan ikan dipengaruhi oleh pasang surut yang mendistribusikan ikan ke berbagai habitat.

Tabel 3. Data Parameter Lingkungan di Segara Anakan Cilacap

\begin{tabular}{lrrrrrrr}
\hline \multirow{2}{*}{ Parameter } & \multicolumn{7}{c}{ Stasiun } \\
\cline { 2 - 8 } & I & II & III & IV & V & VI & VII \\
\hline Salinitas (ppt) & 37 & 36 & 37 & 36 & 37 & 35 & 36 \\
\hline Suhu air $\left({ }^{\circ} \mathrm{C}\right)$ & 27 & 27 & 26 & 26 & 27 & 27 & 26 \\
\hline Suhu udara $\left({ }^{\circ} \mathrm{C}\right)$ & 25 & 24 & 26 & 26 & 25 & 26 & 25 \\
\hline Oksigen terlarut $(\mathrm{mg} / \mathrm{l})$ & 4,6 & 4,5 & 5,2 & 4,7 & 5,6 & 4,6 & 4,7 \\
\hline pH & 7 & 7 & 7 & 7 & 7 & 7 & 7 \\
\hline
\end{tabular}

Hasil pengukuran parameter lingkungan selama pengambilan sampel penelitian disajikan pada Tabel 3. Berdasarkan pada Tabel 3., maka rata-rata suhu air yang diperoleh adalah $26,57^{\circ} \mathrm{C}$ dan suhu udara $25,3^{\circ} \mathrm{C}$, dengan $\mathrm{pH} 7$, kandungan oksigen terlarut berkisar 4,5-5,2 mg/L, salinitas berkisar 35-37 ppt. Kisaran suhu yang di dapat $26-27^{\circ} \mathrm{C}$. Hal ini sesuai dengan pernyataan Saputra (2003) yang menyatakan bahwa suhu permukaan air di daerah Segara Anakan berkisar $26,6-32^{\circ} \mathrm{C}$. Suhu juga merupakan salah satu faktor yang sangat penting dalam pengaturan proses kehidupan dan penyebaran suatu organisme. Hickling (1971) berpendapat bahwa suhu air mempengaruhi seluruh kegiatan kehidupan ikan seperti pernapasan, reproduksi dan pertumbuhan. Pengaruh langsung berupa aktifitas organisme seperti pertumbuhan, reproduksi dan metabolisme, sedangkan pengaruh tidak langsung meliputi meningkatnya daya akumulasi berbagai zat kimia dan menurunkan kadar oksigen dalam air. 


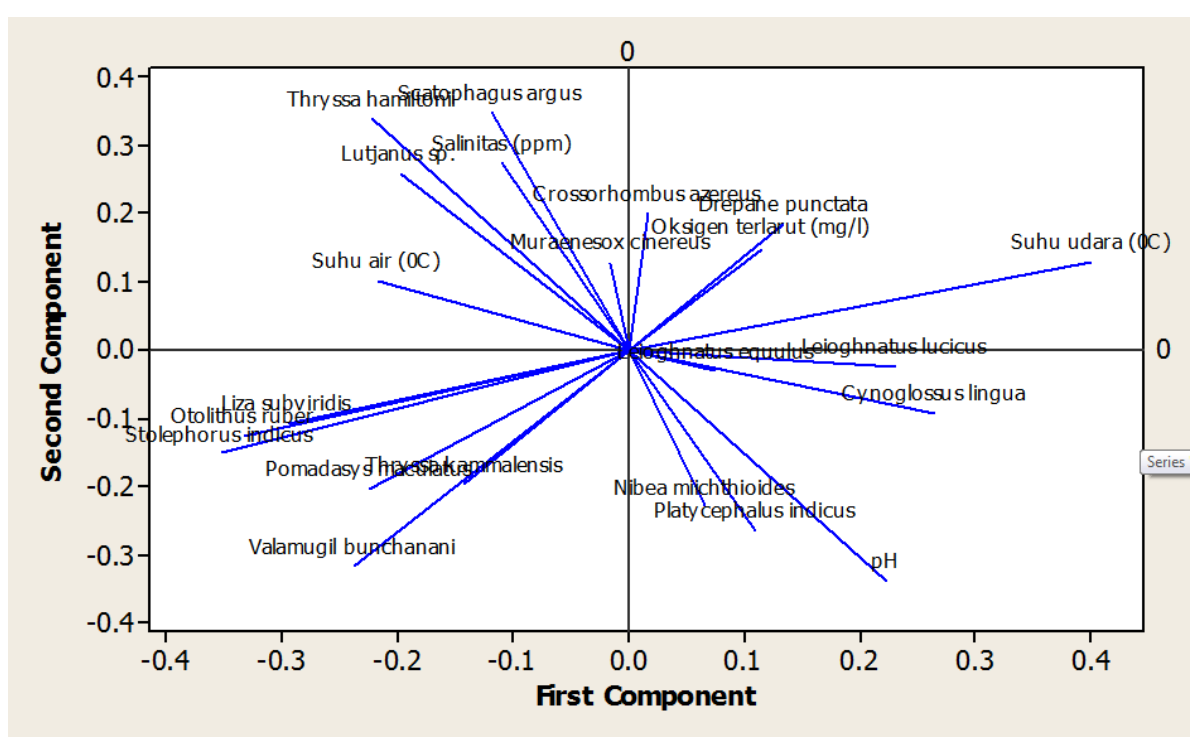

Gambar 2. Grafik Analisis Komponen Utama Karakteristik Stasiun Penelitian

Kisaran DO yang diperoleh 4,5-5,2 mg/L, Wardoyo (1975) mengemukakan kadar DO yang baik untuk ikan tidak boleh kurang dari $4 \mathrm{mg} / \mathrm{L}$ atau kurang akan mengganggu kehidupan ikan maupun hewan air lainnya. Hal tersebut sesuai dengan standar baku mutu perairan, kadar oksigen terlarut (DO) yang baik untuk ikan tidak boleh kurang dari $4 \mathrm{mg} / \mathrm{L}$ (Wardoyo, 1975). Kehidupan makhluk hidup di dalam air tergantung dari kemampuan air untuk mempertahankan konsentrasi oksigen minimal yang dibutuhkan untuk kehidupan (Fardiaz, 1992).

Nilai $\mathrm{pH}$ yang diperoleh yaitu 7 , nilai $\mathrm{pH}$ yang sesuai dengan standar baku mutu perairan berkisar antara 6-9. Kondisi perairan yang bersifat sangat asam atau sangat basa akan membahayakan kelangsungan hidup organisme karena akan menyebabkan terjadinya gangguan metabolisme dan respirasi (Barus, 1996). Pada $\mathrm{pH}$ diatas 8,5 dan di bawah 5 toleransi pada ikan sudah semakin berkurang (Moyle dan Cech, 1988).

Salinitas pada keseluruhan stasiun berkisar 35-37 ppt, hal tersebut tidak sesuai dengan standar baku mutu perairan dimana salinitas berkisar 31,5-34,5 ppt (Tomascik, et al., 1997). Menurut Nybakken (1992) semakin tinggi tingkat penguapan air di suatu wilayah maka salinitasnya akan semakin tinggi begitu pula sebaliknya. Pasang surut laut berpengaruh besar terhadap perubahan salinitas yaitu akan mengalami peningkatan pada saat pasang dan menurun pada saat surut. Adanya perbedaan salinitas pada setiap stasiun penelitian berkaitan dengan suhu pada setiap stasiun. Hal ini dapat membatasi distribusi spesies fauna mangrove salah satunya adalah ikan (Odum, 1993).

Berdasarkan hasil analisis Principal Component Analysis memperlihatkan terbentuknya empat kelompok asosiasi, yaitu: Kelompok pertama dan kedua, merupakan kelompok asosiasi Drepane punctate ,Crossorhombus azereus, Thryssa hamiltonii, Scatophagus argus, Lutjanus sp. dan Trichiurus lepturus. Merujuk pada karakteristik parameter fisik dan kimia dicirikan oleh suhu udara, suhu air, salinitas dan oksigen terlarut. Kelompok tiga dan empat, merupakan kelompok asosiasi Otolithus ruber, Stolephorus indicus, Pomadasys maculatus, Thryssa kammalensis, Valamugil bunchanani, Liza subviridis, Leioghnatus equulus, Cynoglossus lingua, Nibea miichthioides, dan Platycephalus indicus.

Merujuk pada karakteristik parameter fisik dan kimia dicirikan oleh $\mathrm{pH}$. Perbedaan lingkungan dapat berpengaruh pada distribusi dan pertumbuhan suatu spesies. Salah satu contohnya adalah kandungan nutrien dan salinitas, menurut Chen dan Twilley (1998) distribusi dapat terpengaruh karena variasi konsentrasi nutrien yang dapat merubah keseimbangan distribusi suatu spesies.

\section{K E S I M P U L A N}

Diversitas ikan yang terdapat di Segara Anakan Cilacap sebanyak 17 spesies dari 12 familia. Distribusi ikan yang ditemukan adalah bervariasi disetiap stasiun, dengan Stolephorus indicus merupakan spesies yang dominan. Faktor lingkungan berpengaruh terhadap diversitas dan distribusi spasial ikan.

\section{DAFT AR REFERENSI}

Ardli ER, Wolff M. 2008. Quantifying habitat and resource use changes in the Segara Anakan lagoon (Cilacap, Indonesia) over the past 25 years (1978-2004). Asian Journal of Water, Environment and Pollution. 5(4):59-67.

Badola R, Hussain SA. 2005.Valuing ecosystem functions: An empirical study on the storm protection function of Bhitarkanika mangrove ecosystem, India. Environmental Conservation. 32(1):85-92.

Chen R, Twilley RR. 1998. A gap dynamic model of mangrove forest development along gradients of soil salinity and nutrient resources. Journal of ecology. 86(1): 37-51.

Janekarn V, Boonruang P. 1986. Composition and occurrence of fish larvae in mangrove areas along the east coast of Phuket Island; Western Penisular, Thailand. Phuket Marine Biological Center, Phuket Thailand Research Bulletin. 44:22-28. 
Kottelat M, Whitten JA, Wirjoatmodjo S, Kartikasari S. 1996. Freshwater fishes of Western Indonesia and Sulawesi. Jakarta: Periplus Edition Ltd.

Listyaningsih DD. 2011. Bioekologi kerang totok Polymesoda erosa di ekosistem Segara Anakan Cilacap [skripsi]. Fakultas Biologi Universitas Jenderal Soedirman- Purwokerto.

McAleece N. 1997. Biodiversity profesional version 2. New York: The Natural History Museum and Scottish Association For Marine Sciene.

Moyle PB, Cech JJ. 1989. Fishes and introduction to ichytology. New Jersey: Prentice Hall Englewood Cliffs.

Negara AL. 2012. Laguna menyusut, banjir susah surut. Satelite Pos. 2 Desember 2012:10.

Nybakken JW. 1992. biologi laut suatu pendekatan ekologi. Jakarta: PT. Gramedia. 421-459.

Odum EP. 1993. Dasar-dasar ekologi. Samingan T, Srigandono B, penerjemah. Yogyakarta: Gajahmada University Press. 697 hal.

Oemarjati BS, Wardhana W. 1990. Taksonomi avertebrata. Pengantar praktikum laboratorium. Jakarta: Penerbit Unversitas Indonesia press.

Saputra SW. 2003. Kondisi perairan Segara Anakan ditinjau dari indikator biotik [Makalah Pengantar Falsafah Sains]. Program Pasca Sarjana Institut Pertanian Bogor-Bogor.
Setiawan F. 2010. Panduan lapangan identifikasi ikan karang dan vertebrata laut. Wildlife Conservation Society (WCS-IP) Marine Program.

Spellerberg IF. 1991. Monitoring ecological change. New York: Cambridge University Press.

Sugiharto, Siregar AS, Yuwono E. 2006. Analisis isi lambung ikan Pelagis di Segara Anakan Cilacap. Sains Akuatik. 10(2):141147.

Suprapto. 2008. Indeks keanekaragaman hayati ikan Demersial di perairan Arafura. Jakarta: Balai Riset Perikanan Laut, Muara Baru.

Suprayitno. 2001. Distribusi spasial ikan Cyprinidae di sungai Logawa Kabupaten Banyumas Propinsi Jawa Tengah [skripsi]. Fakultas Biologi Universitas Jenderal Soedirman- Purwokerto.

Tomascik T, Mah AJ, Nontji A, Moosa MK. 1997. The ecology of the Indonesian seas part II. Sydney: University of New South Wales Press.

Townsen J, Hughes RN. Distribution of macrofauna on a Malayan mangrove shore. Journal of Animal Ecology. 43:51-59.

Wilhm JL, Doris TC. 1986. Biological parameter for water quality criteria. Bio Science [internet]. [diunduh 29 Mei 2012]. 18. Tersedia pada:http://www.fishbase.Sinica.edu.tw. 